\title{
Quranic and Linguistic Concepts in The Verse: La Uqsimu
}

\author{
Abdulrazzaq Abdulrahman Alsaadi \\ Bolgar Islamic Academy, Republic of Tatarstan, Russia \\ alsaadi.razzaq@gmail.com
}

\begin{abstract}
KEYWORDS: $\quad$ Quranic Concepts, Linguistic Concepts, Oath, Rhetoric, Linguistic Inimitability.
\end{abstract}
Crossref doi https://doi.org/10.51345/.v32i3.447.g232

\begin{abstract}
:
The phrase (La Uqsimu), which means: I do not swear, is repeated eight times in seven Surah in the Nobel Quran. This phrase has been recited in multiple ways (Qira'at). Some of them are correct Qira'at and some of them are abnormal ones that are not for reciting but are cited for linguistic issues, and they are an authentic Arabic style. Scholars have opinions and directions of citing this Arabic style that would achieve the intended meaning, and demonstrate the inimitability of the Nobel Quran through the grammar and rhetoric of the Arabic language. This research comes to present a simplified detail of what was said in this style of Qur'anic expression, a clear statement on this issue, and a cautious analysis of the miraculous connotations in those Qur'anic verses.
\end{abstract}




\title{
مفاهيم قر آنية لغوية في قوله تعالى: (لاَ أُقْسمِم)
}

\author{
أ.د. عبدالرزاق عبدالرحن السعدي \\ أكاديمية بلغار الإسلامية، جهورية تتارستان، روسيا الاتحادية \\ alsaadi.razzaq@gmail.com
}

مفاهيم قر آنية، مفاهيم لغوية، القَسم، البلاغة العربية، الإعجاز اللغوي.

الكلمات المفتاحية

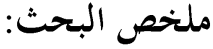

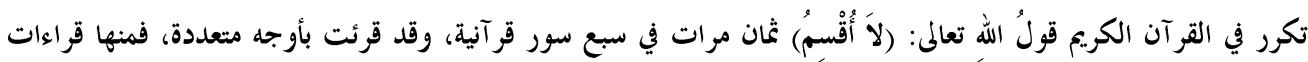

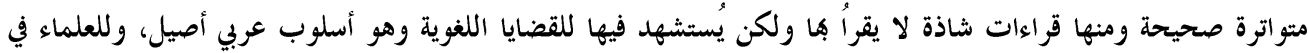

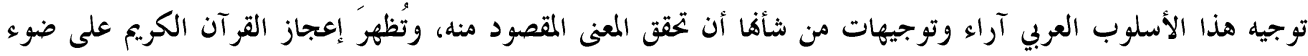

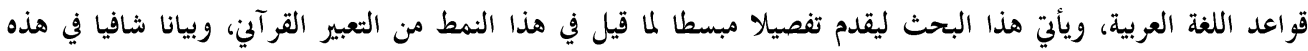

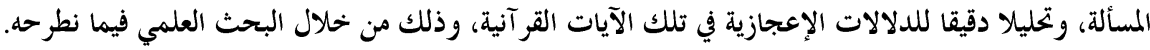

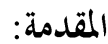

يقرأ المسلمون القر آن الكريم، ويمرون على قراءة آيات فيها قوله تعالى: (لا أقسم)، وحين يتدبرون معاني القرآن الكريم يتوقفون عند هذ هذه العبارة من الآيات القرآنية، فيشكل عليهم تفسير هذا الأسلوب

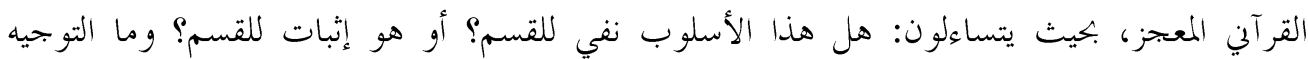

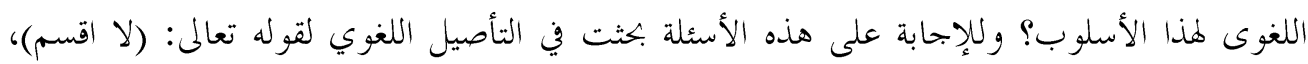

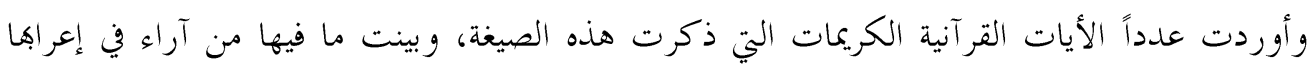
ومعناها. وجدير بالذكر أن صيغة: (لا أقسم) وردت في القرآن الكريم ثمان مرات في سبع سور، في كل سورة ذكرت هذه الصيغة مرة واحدة، إلا في سورة القيامة فقد ذكرت مرتين، وجاء البحث في تحليل هذه الصيغة مستوفيا جميع الوجوه، معزازا فالإحالة إلى المصادر ذات العلاقة هذا الموضوع. 


\section{أولا - الآيات والسور القر آنية التي ورد فيها قوله تعالى: (لا أقسم):}

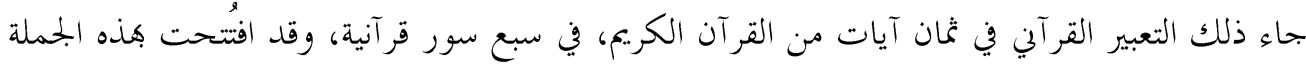

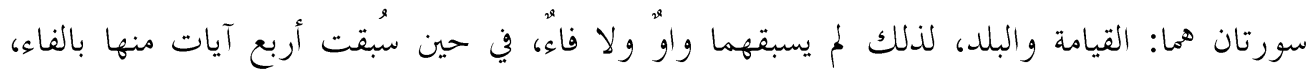
وواحدة منها بالو او: على النحو الآتي:

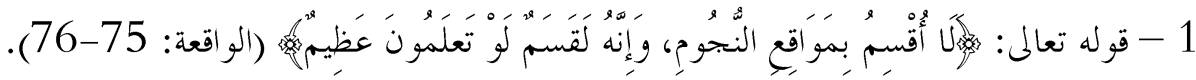

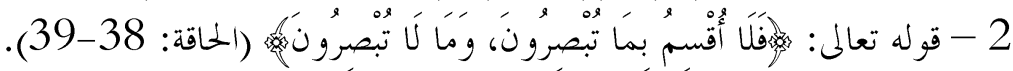

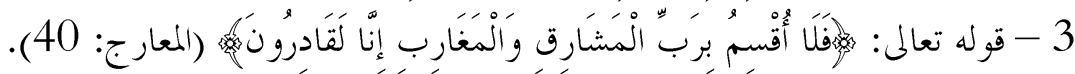
4 - قوله تعالى:

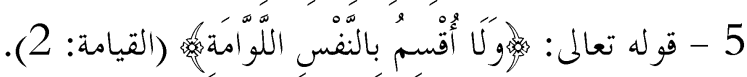

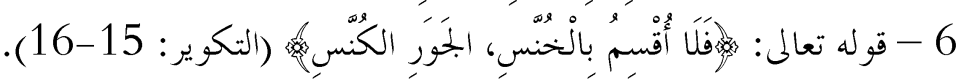

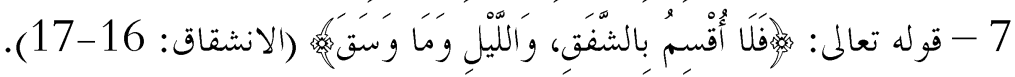

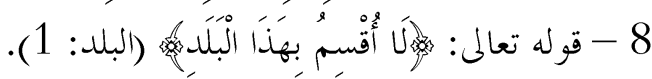

\section{ثانيا - مادة (قسم) في القر آن الكريم:}

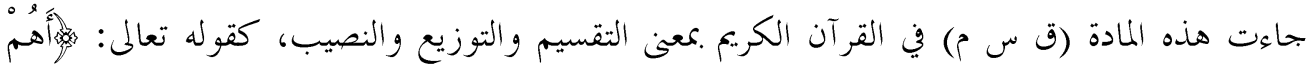

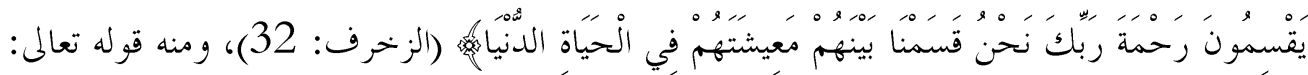

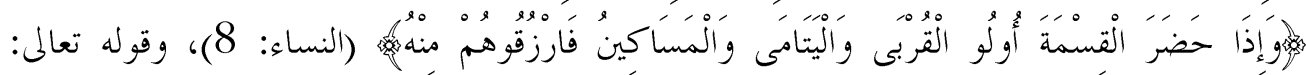

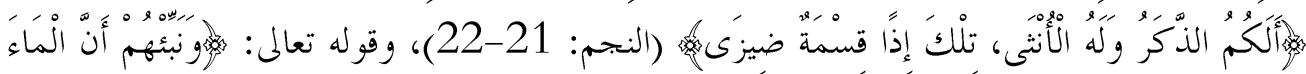

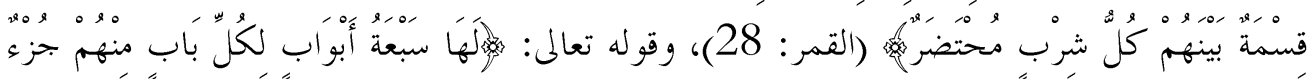

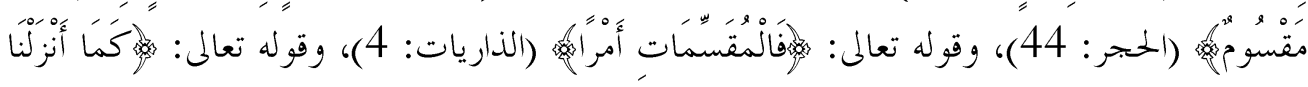

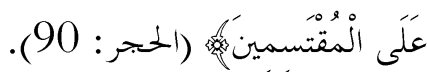

وجاءت مادة (ق س م) في القرآن الكريم أيضا بمعنى اليمين والحَلف، بصيغ متنوعة، فقد جاءت بصيغة

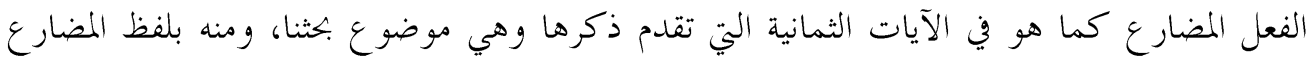

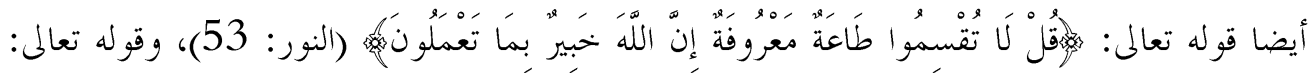

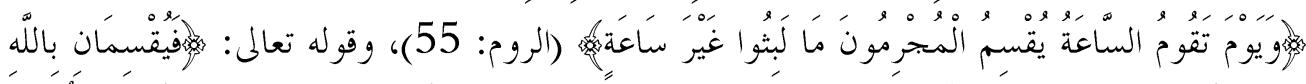

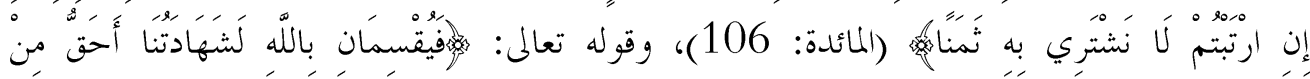




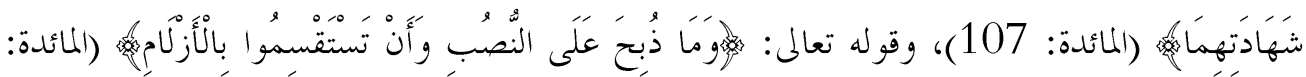

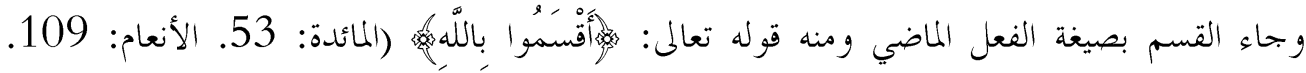

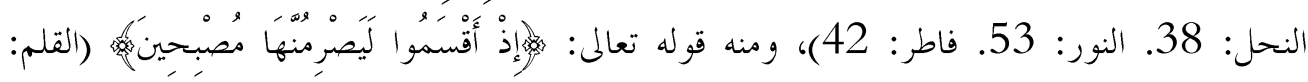

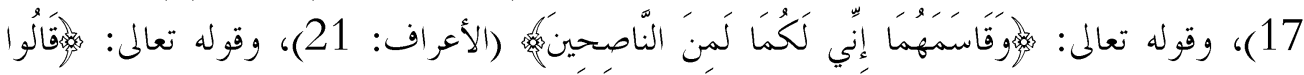

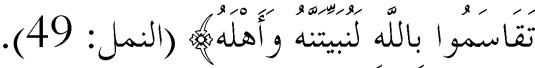

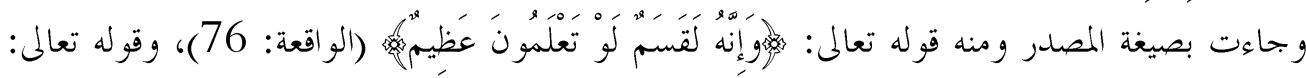

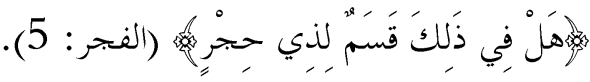

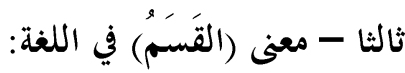

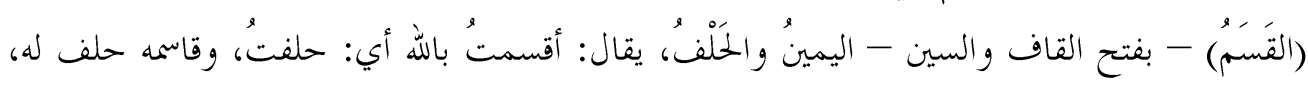

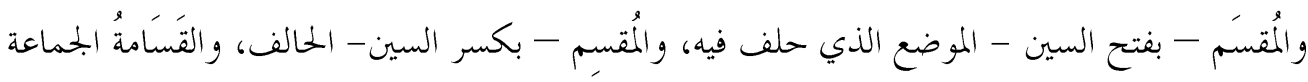

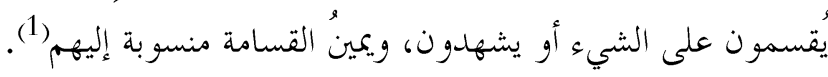
رابعا - قراءات (لا أُقسمُم) وتوجيهها اللغوي النحوي:

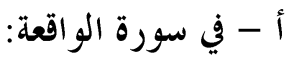

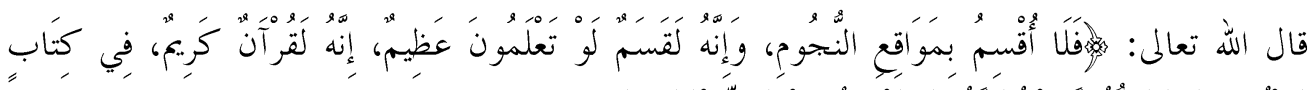

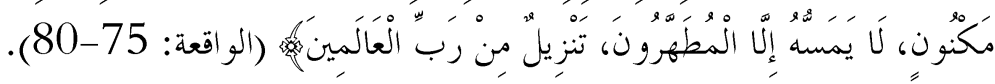

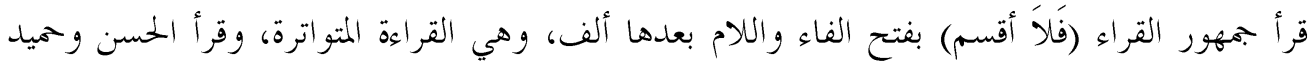

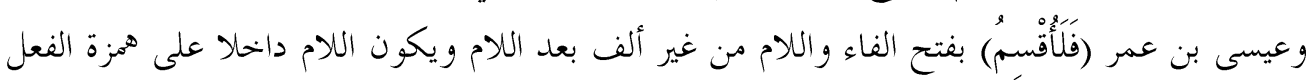

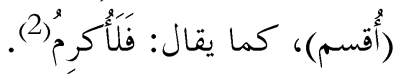

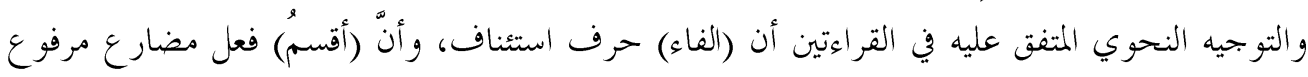

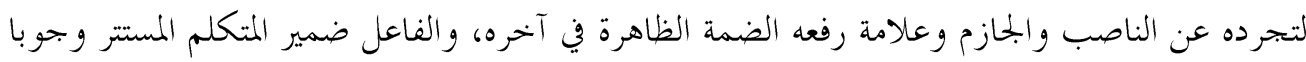

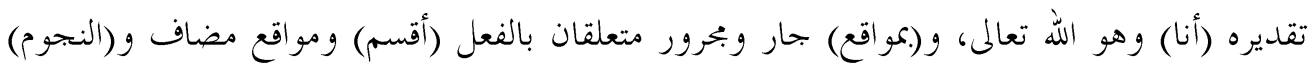

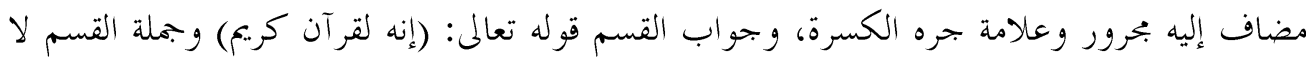

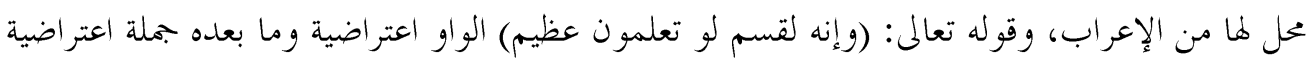

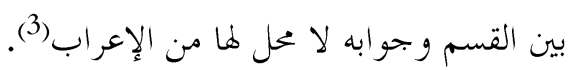




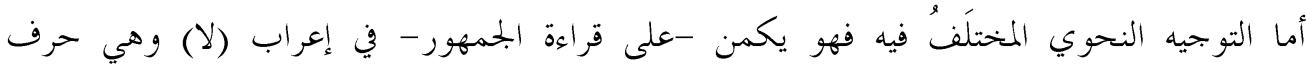

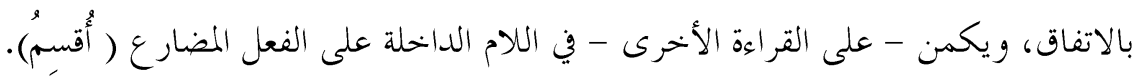
أما إعراب (لا) ففيه الأوجه الآتية:

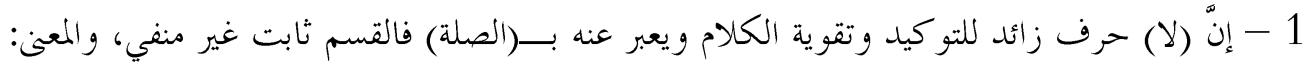

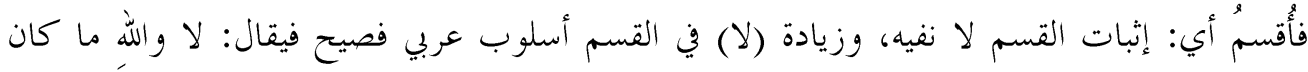

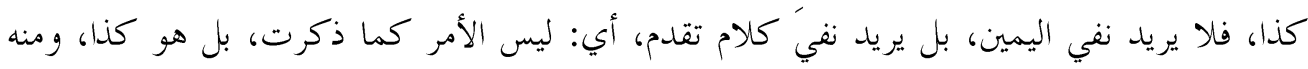
قول امرؤ القيس: - مليس

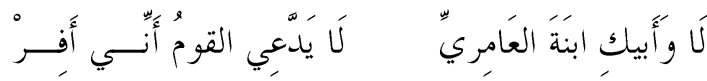
أي: وأبيك ابنة العامري، والواو هنا واو القسم.

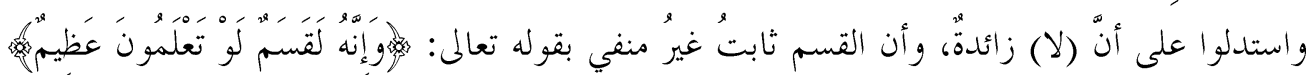

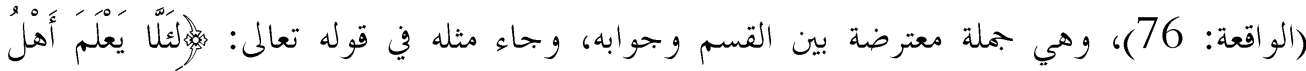

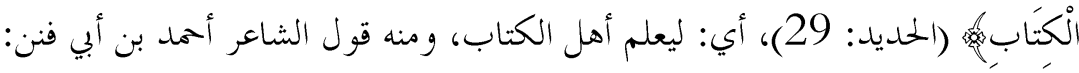

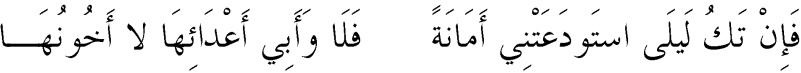

$$
\text { أي: فوأبَّي لا أخوهاب(َ). }
$$

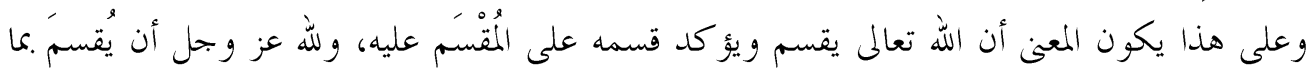

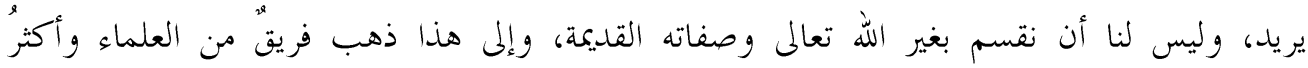
المفسر ين (5). 2 - إنْ (لا) حرف نفي وبه قال الفراء، والكلام المنفي مقدر، وهو كلام الكفار الذين أنكروا صحة

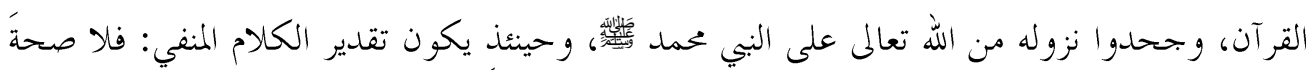

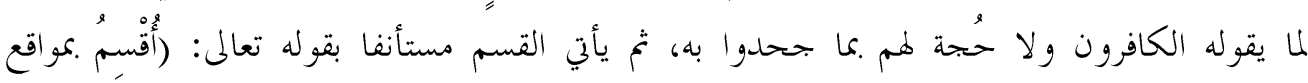

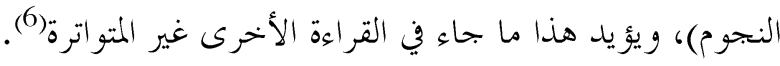

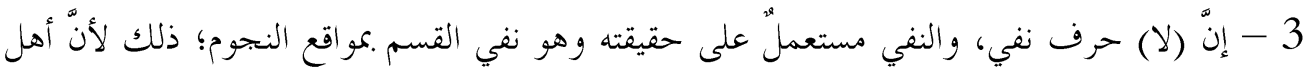

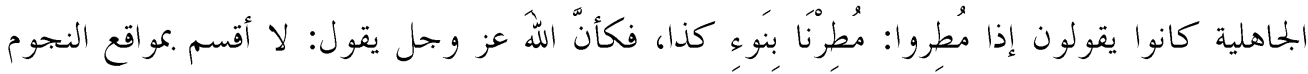

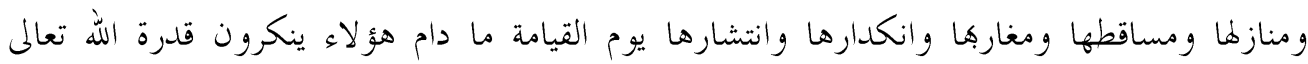

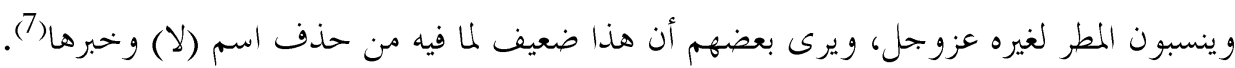

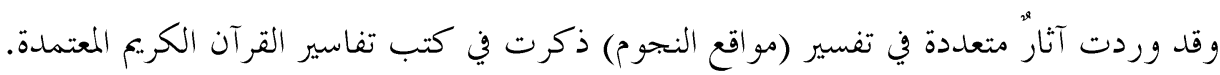




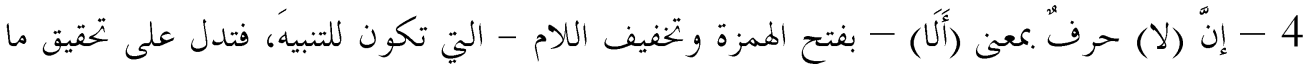
بعدها؛ لأها مركبة من همزة الاستفهام و(لا) وهمزة الاستفهام إذا دخلت على النفي أفادت التحقيق،

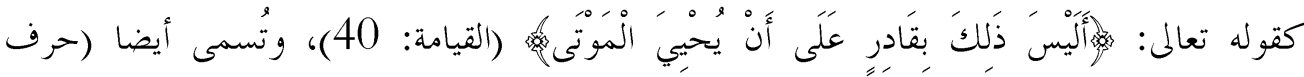
استفتاح) وتدخل على الجملة الإسمية والفعلية(8)، وهو أسلوب عربي فصيح؛ لينبه على فضيلة القرآن

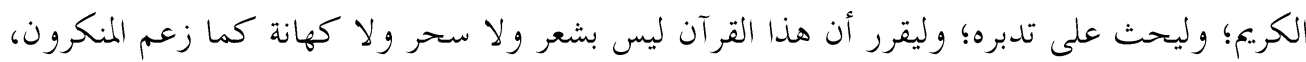
وقد جاء على غرار هذا الإسلوب قولُ امرء القيس في ديو انه:

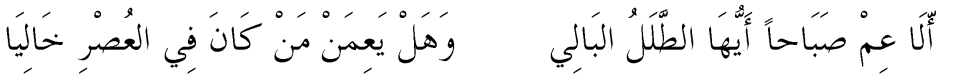

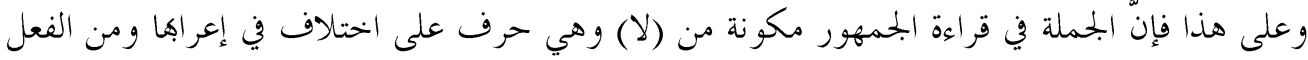

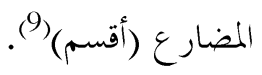

وأما إعراب اللام على قراءة غير الجمهور فكما يأتي:

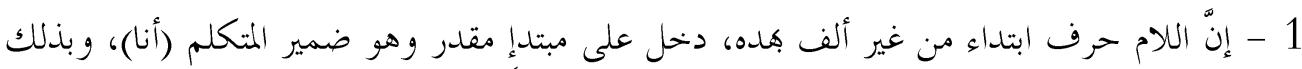

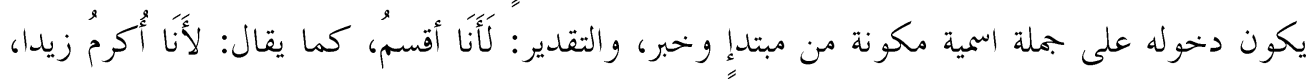

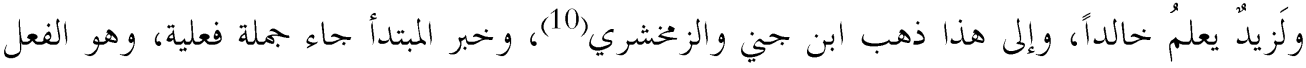

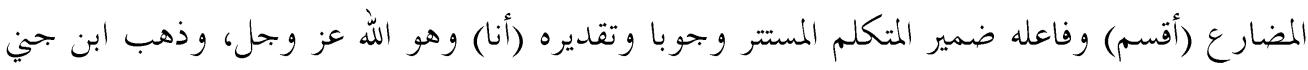

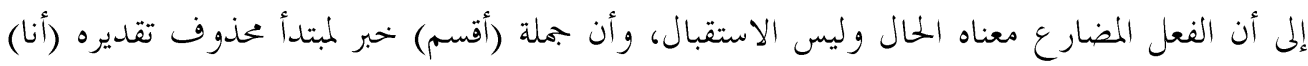

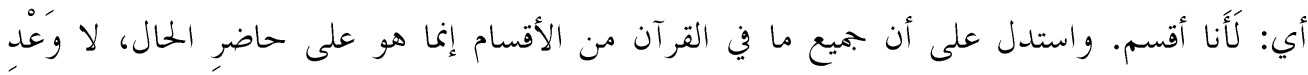

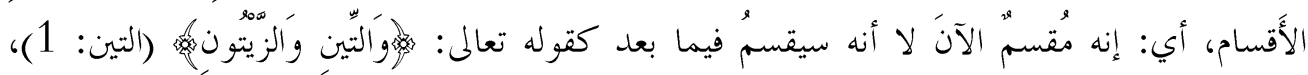

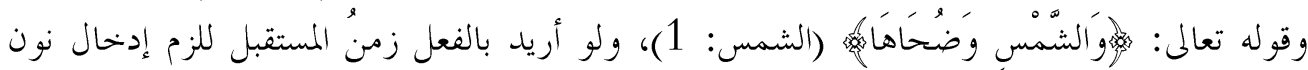

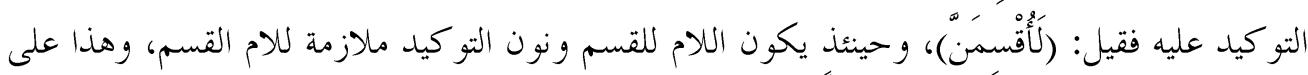

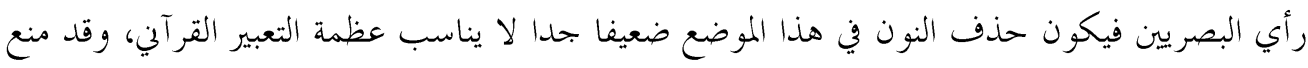

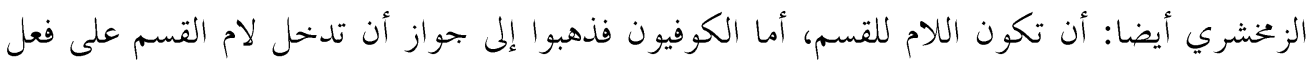
الحال و لا حاجة إلى نون التوكيد(11).

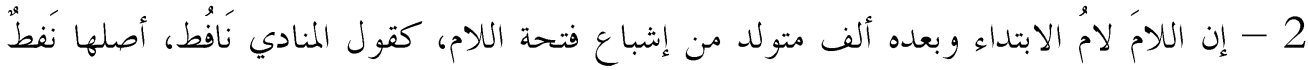

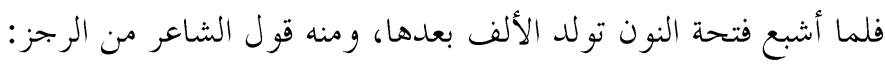

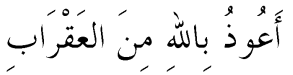


أي: من العقرب، وهذا الوجه ذهب إليه أبو حيان ورجحه، مستشهها بقراءة هشام بقوله تعالى: هابَّفئدة" منَّ النّاس بِهَه (إبراهيم: 37)، بتوليد ياءٍ من كسرة الممزة، لكن شهاب الدين جعل هذا الوجهَ ضعيفا، وعلى هذا فإن الجملة في القراءة الثانية تكون مكونة من لام الابتداء، والمبتدأ المقدر(أنا)، و خحبره الفعل (المضار ع (أقسم)

\section{سياق القسم في قوله تعالم: (فلا أقسم بمو اقع النجوم) الو اقعة: 75}

جاء هذا القسم تفريعاً على آيات ذكرت أنَّ الله تعالى يبعث الناسَّمن القبور من الأولين والآخرين وأن الله تعالى يجمعهمم إلى ميقات يو م معلوم، وذلك ردّاً على المشركين في إنكارهم البعث والنشور، الذي

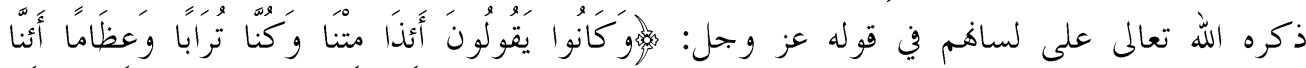

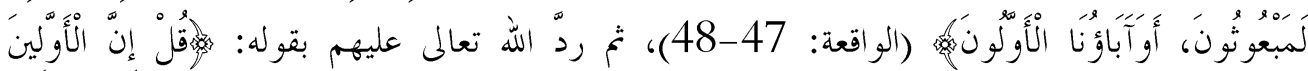

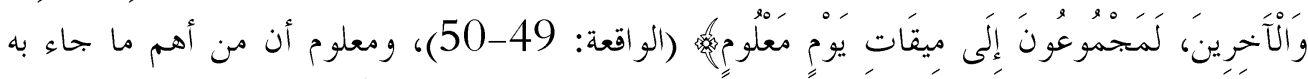

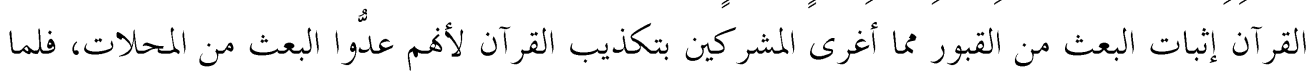
قامت الحجة على خطئهم في تكذيبهم، فقد تبين صدق ما أبأهم به القرآن فثبت صدقه ؛ لذلك جاء القسم على أن القر آن كريم في كتاب مكنون وهو تتزيل من رب العالمين. وعلى هذا فإن من ذهب إلى أن (لا) زائدة للتو كيد فهو صحيح بأن القسم ثابت على أن القرآن منزه عن النقائص وأنه تتزيل رب العالمين وأن الذي جاء به مبلغ عن الله تعالى. وأما على من ذهب أن (لا) نافية فهو صحيح أيضا بأن الله تعالى غير محتاج إلى القسم على ثبوت البعث من القبور؛ لأنَّ الأمر واضح الثبوت، ثم كثر هذا الاستعمال فصار مسلكا لتأكيد الخبر فساوى القسم،

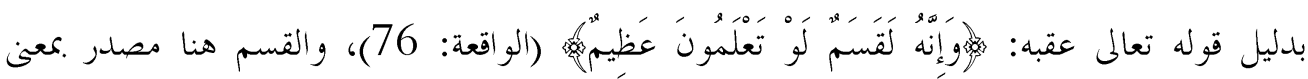
المفعول أي: مقسوم كالخلق بكعنى المخلوق، فالمذكور شيء عظيم يُقسم به المقسمون، قال ابن عاشور: ( وهذا الوجه الثاني هو الأنسب .بما وقع من مثله في القر آن اهــ)(12).

\section{ب - مي سورة الحاقة:}

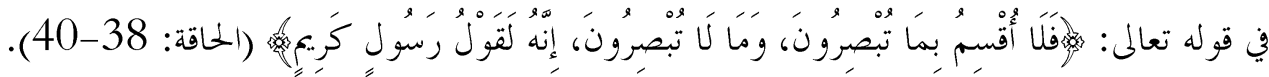
القراءات في هذه الآية وتوجيهها لا يختلف عما تقدم في سورة الواقعة، ويكون المعنى: أقسم بالأشياء كلّها، ما ترون منها، وما لا ترون، على رأي من جعل (لا) صلة زائدة للتو كيد، و كذلك على رأي من جعل (لا) حرف نفي لكام سابق، أي: ليس الأمر كما يقوله المشركون في الطعن بالقرآن الكريم، فإنهّ 


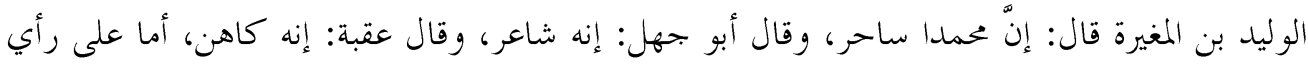

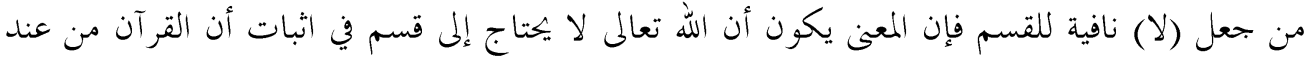

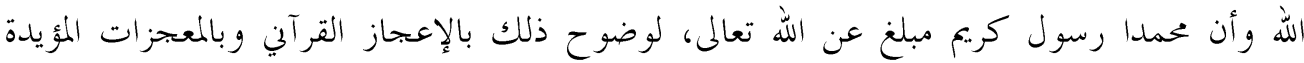

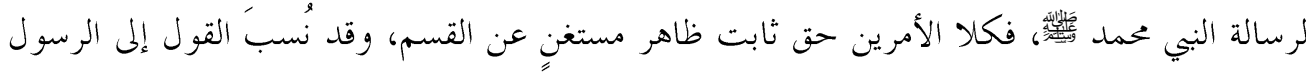

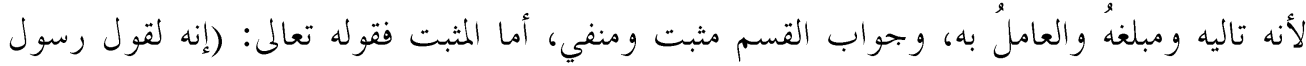

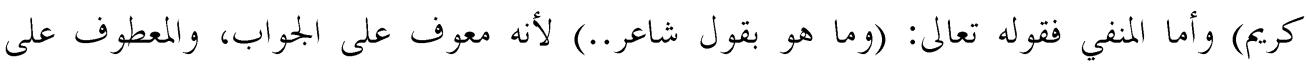
الجواب جوابٌ، وفي هذا بلاغة قرآنية ومعجزة عظيمة(13).

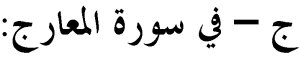

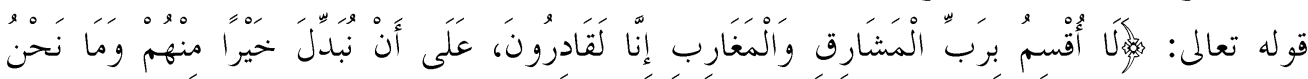

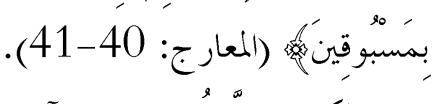

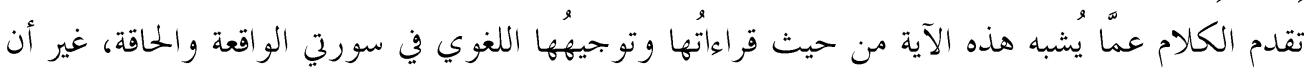

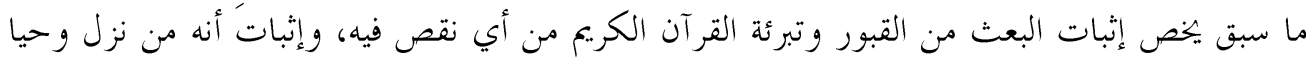

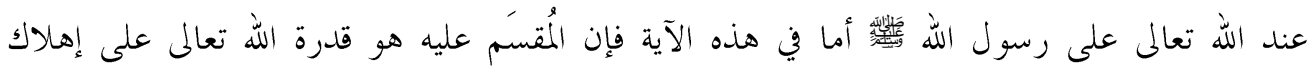
الكفار، والمجيء بخير منهم في الفضل والطاعة والإيمان(14).

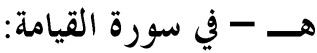

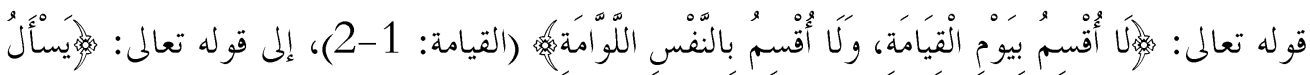

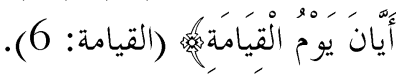

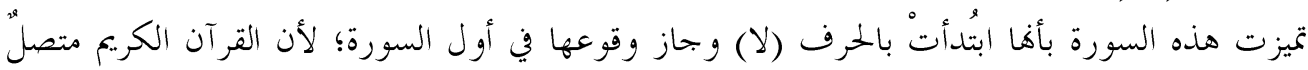

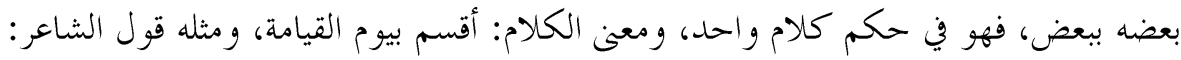

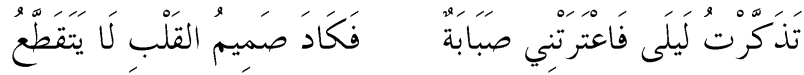

$$
\text { أي: صميم القلب يتقطع (15). }
$$

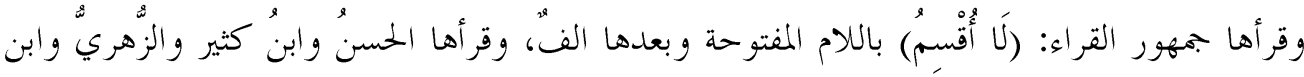

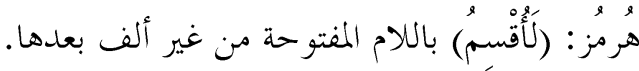

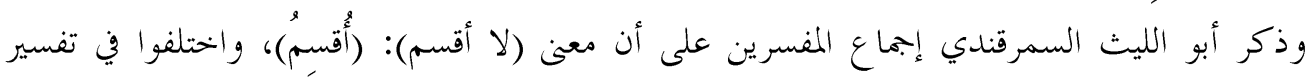

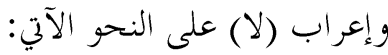


1 - (لا) زائدة في الكلام للزينة و التأكيد، وزيادةا أسلوب عربي وارد في كلام العرب، ومثله في القرآن

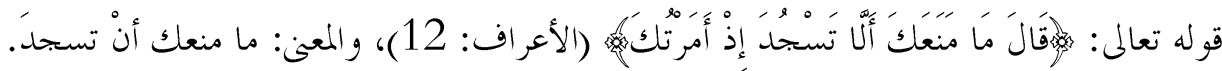
2 - (لا) حرف نفي للرد على منكري البعث من القبور، أي: ليس الأمر كما زعمتم، وهذا قال

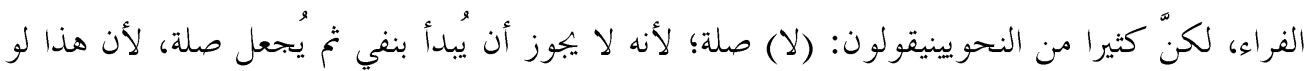

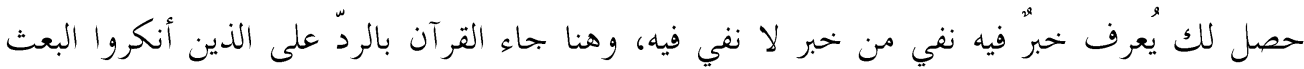

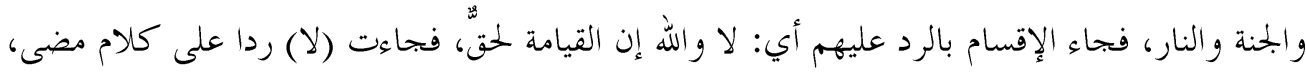

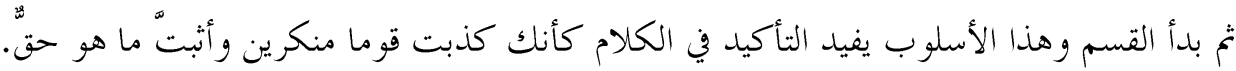

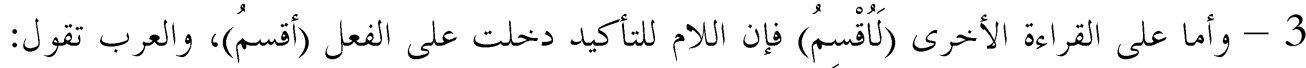
لأقسم بالله. أما قوله تعالى: (وكَا أقسم بالنفس اللوامة) فلا خلاف بين القراء بأها (لا) باللام والألف، وعلى هذا

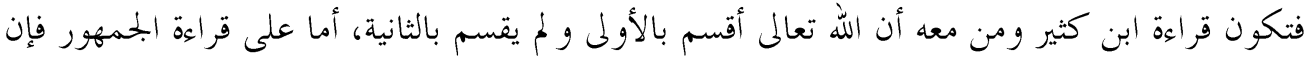
الله تعالى أقسم بشيئين هما يوم القيامة والنفس اللو امة معن.

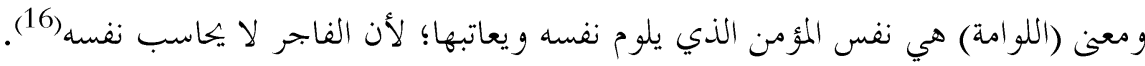

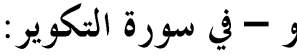

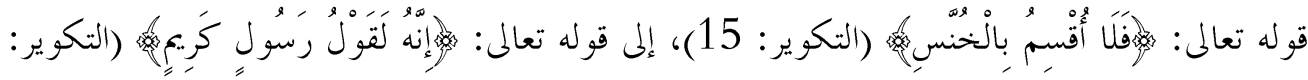

الكلام في هذه الآية لا يختلف عمّا تقدم من القراءات والتوجيهات، والخنس نوع من الكواكب التي تخنس في النهار، و الكنس التي تستتر عن الأنظار، وعسعس الليل إذا أقبل بظلامه أو أدبر، وتنفس لهن الصبح إذا انشق و انفلق بياضه(17).

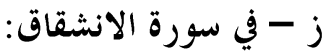

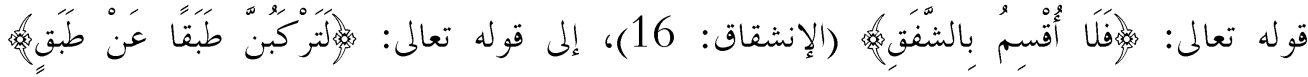
(الإنشقاق: 19) (ل) الشفق الحمرة التي ترى عند المغرب بعد غياب الشمس، والليل وما وسق أي وما جمع وضم ولفَّ،

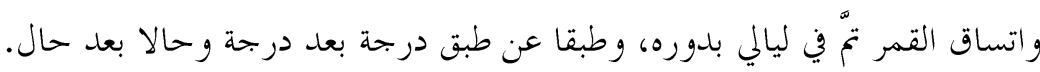
و الكلام عن ( فلا أقسم) شبيه بما تقدم من أمثاله. 


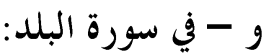

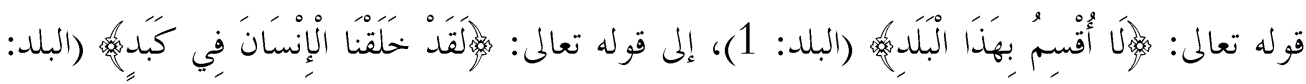
$\cdot(4$ والكلام في (لا أقسم) كما تقدم في سورة القيامة والمقصود بالبلد مكة المكرمة أي: أقسم بالبلد الحرام الذي أنت فيه يا محمد.

النتائج:

توصل هذ البحث إلى نتائج عديدة ومنها ما يأتي:

1- إن القرآن الكريم نزل قرآنا عربيا مواكبا لأفصح لغات العرب في في أساليب التعبير.

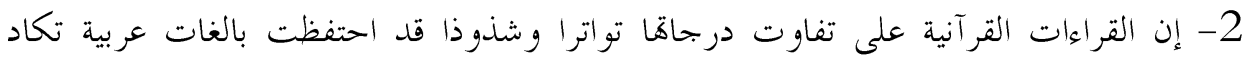
تكون قد اندثرت.

3- إن عبارة (لا أقسم) تكررت في القرآن الكريم ثمان مرات في سبع سور قرآنية. 4- إن قوله تعالى: (فلا أقسم) تعبير عربي فصيح وله توجيهات إعرابية لعدد من علماء البصرة وعلماء الكوفة. 5- حمل هذا التعبير القرآي (لا أقسم) معان لغوية ونحوية وبلاغية متعلددة.

التوصيات: أوصي القائمين على وضع المناهج الدراسية في أقسام اللغة العربية وأقسام الشريعة، أن يجعلوا ساعات دراسية تعنى بالإعجاز اللغوي للقرآن الكرين من خحالال ربط النص بقواعد اللغة العربية.

المصادر: 1. 2.

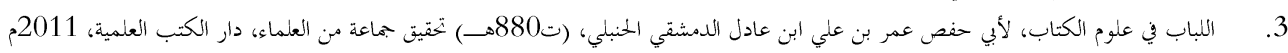
$428 / 18$

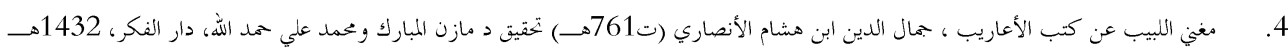

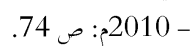
المحتسب في تبين وجوه شواذ القراءات والإيضاح عنها لآبي الفتح عثمان بن جني، نتقيق علي النجدي ناصف والدكور عبد الفتاح إسماعيل شليي، .5

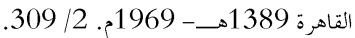

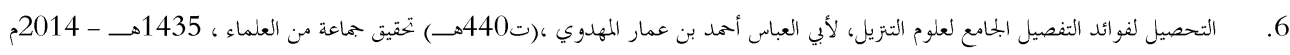

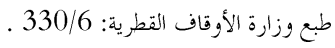




$$
\text { (2) تفسير القرطبي: 217/20 العرب، لابن منظور (قسم). }
$$

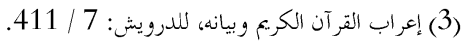

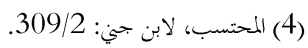

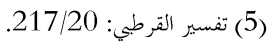

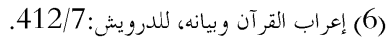

(7) اللباب في علوم الكتاب، لابن عادل: 428/18.

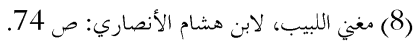

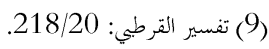

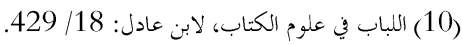

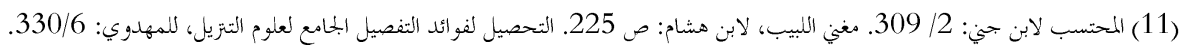

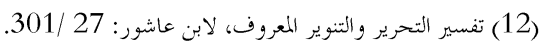

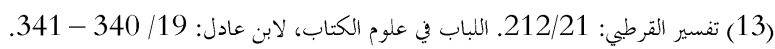

245/21.

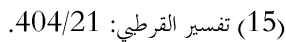

(16) تفسير القرطبي: 406/21. تلنسير اللباب في علوم الكتاب، لابن عادل: 541/19.

109/22. 